\title{
Produção científica sobre a covid-19 na ciência da informação no Brasil: uma pesquisa na Brapci
}

\author{
Scientific production about covid-19 in Brazilian information science field: \\ research in the Brapci
}
Producción científica sobre la covid-19 en la ciencia de la información en Brasil: una investigación en la Brapci

\author{
João Arlindo dos Santos Neto ${ }^{1, a}$ \\ santosneto@uel.br | https://orcid.org/0000-0003-1833-911X \\ 1 Universidade Federal do Pará, Instituto de Ciências Sociais Aplicadas, Faculdade de Biblioteconomia e Programa de \\ Pós-Graduação em Ciência da Informação. Londrina, PR, Brasil. \\ a Doutorado em Ciência da Informação pela Universidade Estadual Paulista.
}

\section{RESUMO}

Os estudos métricos da informação permitem a visualização tanto da produção científica num campo de estudo quanto do comportamento de determinadas comunidades científicas e seus veículos de comunicação. O artigo tem como objetivo geral investigar o cenário da produção cientifica sobre a covid-19 no campo da ciência da informação. Como objetivos específicos, a proposta é: identificar os periódicos que publicaram artigos sobre a temática e aqueles com maior número de publicações acerca do assunto; conhecer os autores mais produtivos e o perfil da constituição das autorias; elencar as palavras-chave mais empregadas nos artigos e as temáticas neles abordadas. Apresenta uma pesquisa básica, do tipo exploratória com delineamento bibliográfico a partir dos artigos indexados na Base de Dados em Ciência da Informação (Brapci) no período de 2020 a maio de 2021. Como resultados, o estudo identifica 178 artigos publicados em periódicos científicos que tratam da temática Covid-19 e apresenta 13 categorias temáticas que contemplam a diversidade de temas abordados pelos profissionais da área. Considera que, além dos estratos do Qualis Periódicos, outros elementos foram levados em conta pelos autores no momento da escolha do periódico em que o artigo seria publicado, como a chamada para números temáticos e dossiês especiais, e ainda o foco e o alcance da revista. Conclui que o esforço da comunidade científica da ciência da informação e áreas afins para publicar sobre a temática relativa à covid-19 configura-se tanto como uma tendência, por se tratar de uma temática emergente em meio à pandemia, quanto como uma demonstração da necessidade de tratar de assuntos a ela relacionados, reforçando o caráter social da ciência da informação.

Palavras-chave: Produção científica; Estudos métricos da informação em saúde; Covid-19; Coronavírus; Pandemia. 


\section{ABSTRACT}

The metric studies of information allow the visualization both of scientific production in a field of study and of the behavior of certain scientific communities and their vehicles of communication. The general objective of this article is to investigate the scenario of scientific production about covid-19 in the field of information science. As specific objectives, it aims to identify the journals that published articles on the theme and those with the largest number of publications on that subject; to know the most productive authors and the profile of the constitution of the authorship; to list the keywords most used in the articles and the themes addressed in the articles. It presents a basic exploratory research, and a bibliographic outline from the articles indexed in the Brapci - Base de Dados em Ciência da Informação (Database in Information Science) during the period from 2020 to May 2021. Two outcomes can be seen: the study identifies 178 articles published in scientific journals which deal with the theme Covid-19 and presents 13 thematic categories revealing the diversity of themes addressed by the authors. It considers that in addition to the classification by Qualis Periódicos, other elements were taken into account by the authors in order to choose the periodical in which the article would be published, such as the call for thematic and special editions, as well as the focus and scope of the journal. It concludes that the effort of the scientific community involved with information science and related fields to publish on the theme covid-19 is configured both as a trend, since it is an emerging theme in an environment where the pandemic is growing, and as an expression of the need to deal with issues related to it, corroborating the social character of information science.

Keywords: Scientific production; Metric studies of health information; Covid-19; Coronavirus; Pandemic.

\section{RESUMEN}

Los estudios métricos de la información permiten visualizar tanto la producción científica en un campo de estudio como el comportamiento de determinadas comunidades científicas y sus vehículos de comunicación. $\mathrm{El}$ artículo tiene como objetivo general investigar el escenario de la producción científica sobre la covid-19 en el campo de la Ciencia de la Información. Como objetivos específicos, la propuesta es: identificar las revistas que publicaron artículos sobre el tema y aquellas con mayor número de publicaciones acerca del asunto; conocer los más productivos autores y el perfil de constitución de autorías; inventariar las palabras clave más utilizadas en los artículos y los temas que ellos abordan. El estudio consiste en una investigación exploratoria básica con esbozo bibliográfico a partir de los artículos indexados en la Brapci - Base de Dados em Ciência da Informação (Base de Datos de Ciencia de la Información) en el período desde 2020 hasta mayo de 2021. Como resultados, el estudio identifica 178 artículos publicados en revistas científicas que abordan el tema Covid-19 y presenta 13 categorías temáticas que exponen la diversidad de temas abordados por los profesionales del área. Considera que, además de los estratos del Qualis Periódicos, los autores tomaron en cuenta otros elementos en la ocasión de elegir el periódico en lo cual se publicaría el artículo, como por ejemplo la convocatoria de números temáticos y dossieres especiales, y también el enfoque y el alcance de la revista. Se concluye que el esfuerzo de la comunidad científica de la Ciencia de la Información y demás áreas relacionadas para publicar acerca de la temática asociada con la covid-19 se configura como una tendencia, por se tratar de un tema emergente en un ambiente de diseminación de la pandemia, y igualmente como una demonstración de la necesidad de abordar temas relacionados con este, corroborando el carácter social de la Ciencia de la Información.

Palabras clave: Producción científica; Estudios métricos de la información sobre la salud; Covid-19; Coronavirus; Pandemia. 
Este artigo compõe o dossiê Estudos métricos da informação científica em saúde, parte 2.

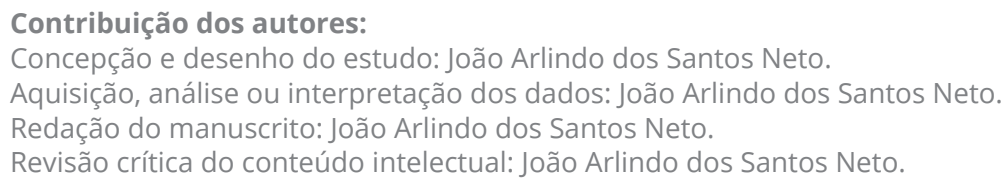

Licença CC BY-NC atribuição não comercial. Com essa licença é permitido acessar, baixar (download), copiar, imprimir, compartilhar, reutilizar e distribuir os artigos, desde que para uso não comercial e com a citação da fonte, conferindo os devidos créditos de autoria e menção à Reciis. Nesses casos, nenhuma permissão é necessária por parte dos autores ou dos editores.

\section{INTRODUÇÃO}

A pandemia de covid-19, causada em virtude do novo coronavírus identificado em humanos pela primeira vez em dezembro de 2019 na cidade de Wuhan, na China, conhecido também por SARS-CoV-2, tem devastado a população mundial numa escala gigantesca desde abril de 2020, e até 12 de julho de 2021 foram registradas 4,19 milhões de mortes (COVID-19..., c2021). Devido à necessidade de isolamento social, lockdown em alguns países, e ao fechamento temporário de muitos estabelecimentos que ainda persiste em muitos setores, o que se viu e ainda se nota em julho de 2021 é a transformação no comportamento dos indivíduos e a continuidade das atividades de forma remota. "A repercussão da covid-19 levou a sociedade médica, farmacêutica e científica, com o apoio de editoras, a publicar sobre o assunto em tempo recorde". (TORRES PASCUAL; TORRELL-VALLESPÍN, 2020, p. 3, tradução nossa). Os referidos autores salientam ainda que é necessário que haja investigações em outras disciplinas.

Ressalta-se também que, mesmo não sendo o foco do presente artigo, é possível identificar na literatura científica o esforço empreendido pelas instituições de ensino e pesquisa, unidades de informação e suas comunidades científicas no enfrentamento à desinformação quanto à pandemia da covid-19. Os pesquisadores e estudantes empreenderam esforços para realizar estudos e investigações que vinculassem tanto suas temáticas de pesquisa quanto a pandemia, sendo alguns, obviamente mais aplicados como é o caso daqueles deflagrados nas ciências da saúde, como também aqueles no escopo das ciências humanas e sociais aplicadas. Assim, este artigo intitulado 'Produção científica sobre a covid-19 na ciência da informação no Brasil: uma pesquisa na Brapci' é apresentado no dossiê Estudos métricos da informação científica em saúde do periódico científico Revista Eletrônica de Comunicação, Informação e Inovação em Saúde (Reciis), da Fundação Oswaldo Cruz (Fiocruz), e tem como objetivo investigar o cenário da produção científica na ciência da informação (CI) a partir de alguns aspectos dos estudos métricos.

Segundo Bufrem (2020, p. 103) "[...] a produção e a comunicação científicas são fatores cruciais para compreender a doença e seus efeitos, na busca de soluções possíveis, se não efetivas ao menos redutoras 
de riscos”. Assim, a produção e a comunicação científica impactam o desenvolvimento científico e cabe aos estudos métricos da informação (EMI), entre outros aspectos, inferir diversos discursos e elementos. Justifica-se a realização deste estudo tendo em vista que o volume de artigos publicados sobre o SARSCoV-2, em poucos meses, tem permitido a realização e publicação de EMI sobre o assunto (TORRES PASCUAL; TORRELL-VALLESPÍN, 2020).

Os estudos métricos da informação, independentemente da sua especificidade, permitem a visualização de um panorama científico, do estado da arte de uma determinada disciplina ou de um campo do conhecimento e a análise do domínio. Tais estudos, quando analisados sob uma ótica estratégica e gerencial, por exemplo, constituem-se como importantes dados para a formulação de políticas públicas e direcionamento de financiamentos de pesquisa, prospecção de cenários, definição de metas e estratégias etc. (OLIVEIRA, 2018; OLIVEIRA; ARAÚJO, 2020; OLIVEIRA; GRÁCIO, 2011; NORONHA; MARICATO, 2008). Além disso, configuram-se um domínio metacientífico (FREITAS; BUFREM; GRÁCIO, 2019), visto que fazem uso de metodologia científica para compreender a própria ciência e seus desdobramentos a partir de vários domínios. A ciência da informação (CI) é uma área que tem nos EMI uma de suas preocupações, seja no âmbito da bibliometria, da cientometria, da informetria, da webometria, da arquivometria, entre outros. De forma genérica, os EMI evidenciam os autores mais produtivos ou mais citados, a constituição das autorias das produções, a prática de cocitação e o acoplamento bibliográfico, os canais de comunicação com maior número de produções sobre determinado tema, o impacto das métricas alternativas, entre outros.

No âmbito da saúde, identificam-se foros privilegiados na CI em que a temática é debatida profundamente. Como exemplo, é possível mencionar o Grupo de Trabalho (GT) 11 da Associação Nacional de Pesquisa em Ciência da Informação (Ancib), intitulado Informação e Saúde, criado em 2011 na $12^{\mathrm{a}}$ edição do Encontro Nacional de Pesquisa e Pós-Graduação em Ciência da Informação (Enancib), e o Seminário Internacional de Informação para a Saúde (Sinforgeds) que, em 2021, chega à sua $6^{\mathrm{a}}$ edição. Além disso, há o Programa de Pós-Graduação em Informação e Comunicação em Saúde (PPGICS), do Instituto de Comunicação e Informação Científica e Tecnológica em Saúde (Icict) da Fundação Oswaldo Cruz (Fiocruz). O referido Programa é avaliado na área interdisciplinar da Coordenação de Aperfeiçoamento de Pessoal de Nível Superior (Capes) e tem como área de concentração: Configurações e Dinâmicas da Informação e Comunicação em Saúde; e como linhas de pesquisa: 1) Produção, Organização e Uso da Informação em Saúde; e 2) Informação, Comunicação e Mediações em Saúde. Por fim, destacam-se a Revista Eletrônica de Comunicação, Informação \& Inovação em Saúde (Reciis) e a Revista Cubana de Información en Ciencias de la Salud. É fato que existem outros foros técnico-científicos que discutem a informação em saúde, no entanto, não o fazem de modo explícito conforme os exemplos mencionados, que carregam em suas nomenclaturas o termo 'saúde'.

No âmbito da CI, estudos que investigam a informação em saúde são uma realidade e constituem-se tanto uma tendência quanto uma necessidade. Afirma-se isso ao identificar o movimento de pesquisadores da CI que confirmam a preocupação existente na produção de conhecimento científico e na ciência voltados para uma dada realidade. Como exemplo e, atendendo a demanda atual - discutir sobre a pandemia da covid-19 em virtude do novo coronavírus -, os EMI científica em saúde foram realizados e continuarão sendo. Assim, além das investigações voltadas especificamente para os fluxos de informação e comportamento informacional dos indivíduos na pandemia covid-19, pesquisadores da CI debruçam-se também sobre outras doenças presentes ainda de forma expressiva no Brasil e sobre estudos que envolvem a saúde de forma geral. Como exemplo, cabe citar Santin, Nunez e Moura (2015), que escreveram 'Produção científica brasileira em células-tronco nos anos 2000 a 2013: características e colaboração internacional'; Martins (2016), que realizou uma 'Análise bibliométrica de artigos científicos sobre o vírus zika'; Sobral et al. (2016), responsáveis por 'Produção científica colaborativa na área da saúde tropical: uma análise da rede de 
colaboração do Programa de Pós-Graduação em Medicina Tropical da Universidade Federal de Pernambuco'; Alencar et al. (2017), autoras de 'Análise da produção científica brasileira sobre nanotecnologia e saúde'; Araújo et al. (2017), que pesquisaram 'A Produção científica sobre zika em periódicos de acesso aberto'.

Ao pesquisar os EMI em saúde voltados especificamente para a pandemia de covid-19, sem aplicação a alguma disciplina ou área do conhecimento, identificaram-se vários estudos. Até o período da coleta (maio de 2021), destacam-se os autores e seus respectivos artigos: Bermúdez-Rodrígueza et al. (2020) - 'O impacto do acesso aberto na produção e difusão de conhecimento sobre a covid-19'; Costa et al. (2020) - 'Produção científica em periódicos online sobre o novo coronavírus (covid-19): pesquisa bibliométrica'; Ortiz-Núñez (2020) - 'Análisis métrico de la producción científica sobre covid-19 en Scopus'; Torres Pascual e Torrell-Vallespín (2020) - 'Análisis bibliométrico de la producción científica latinoamericana y del Caribe sobre covid-19 en PubMed'; Vitón-Castillo et al. (2020) - 'Producción científica sobre covid-19 en revistas estudiantiles cubanas'. Além dessas, existem outras produções que, devido à delimitação do estudo, não compuseram a presente discussão.

A partir do panorama exposto, não foi identificada ainda uma pesquisa que tenha investigado a produção científica sobre a covid-19 especificamente na ciência da informação. Assim, tem-se como objetivos específicos: identificar os periódicos que publicaram artigos sobre essa temática e aqueles com maior número de publicações; conhecer os autores mais produtivos e o perfil da constituição das autorias; as palavras-chave mais empregadas; e as temáticas abordadas nos artigos.

\section{PROCEDIMENTOS METODOLÓGICOS}

O artigo é de natureza básica, pois não vislumbra aplicação prática nem a resolução de problemas específicos. Além disso, mesmo sendo uma pesquisa básica, objetiva gerar conhecimentos relacionados a problemas específicos, como é o caso da pandemia de covid-19. É do tipo exploratório, pois busca a visualização do panorama científico sobre uma determinada temática; e emprega a abordagem qualiquantitativa, em que se faz o uso tanto de fórmulas matemáticas e de recursos que evidenciem os aspectos numéricos, quanto também discutirá tais índices num plano subjetivo e conceitual (GIL, 2008; VALENTIM, 2005; VOLPATO, 2004). Adota como método a pesquisa bibliográfica, para se conhecer o estado da arte sobre a temática na CI (PINTO; CAVALCANTE, 2015) e utiliza delineamentos dos EMI, como a bibliometria e a cientometria (SANTOS; KOBASHI, 2009; SILVA; HAYASHI; HAYASHI, 2011), que buscam tanto a quantidade de revistas científicas em um determinado contexto quanto a dinâmica da ciência de maneira abrangente, incluindo as atividades de produção, circulação e consumo da produção científica. Além disso, optou-se pela Lei de Price para delimitação do corpus. "Segundo esta lei, se k representa o número total de contribuintes numa disciplina, $\sqrt{ } \mathrm{k}$ representaria a elite da área estudada [...]” (URBIZAGÁSTEGUI ALVARADO, 2009, p. 70).

Tem como locus de pesquisa a Base de Dados em Ciência da Informação (Brapci), idealizada pela Universidade Federal do Paraná (UFPR) e, há alguns anos, em convênio com a Universidade Federal do Rio Grande do Sul (UFRGS). A escolha pela Brapci se deve à sua expressividade no âmbito nacional e à sua abrangência no campo da CI, visto que indexa periódicos sem distinção de Qualis, por exemplo.

A pesquisa bibliográfica se deu a partir da busca dos termos "covid" OR "Covid-19" OR "coronavírus" OR "pandemia" OR "SARS-CoV-2" no campo título, no período de 2020 a 2021. A coleta foi realizada nos meses de março, abril e maio de 2021 e contempla as publicações realizadas até esse período. O total de resultados obtidos nas buscas é apresentado na tabela a seguir. 
Tabela 1 - Resultados de busca na Brapci

\begin{tabular}{lcc}
$\begin{array}{l}\text { Termos buscados } \\
\text { no campo "Título" }\end{array}$ & Período & Total \\
\hline "covid" & $2020-2021$ & 121 \\
"covid-19" & $2020-2021$ & 122 \\
"coronavírus" & $2020-2021$ & 22 \\
"pandemia" & $2020-2021$ & 69 \\
"SARS-CoV-2" & $2020-2021$ & 7 \\
Total & & $\mathbf{3 4 1}$ \\
\hline
\end{tabular}

Fonte: elaboração do autor.

Após análise inicial dos 341 resultados, verificou-se que há artigos com registro duplicados na base, editoriais de periódico, trabalhos publicados em anais de evento e artigos que contêm no título mais de um dos termos buscados. Assim, após tabulação e ordenação dos dados em planilha de edição de dados (Microsoft Excel) chegou-se a um total de 178 artigos, que passaram a constituir a amostra da pesquisa.

Os resultados objetivos (quantificação dos dados) são discutidos em panoramas mais subjetivos (interpretação e contextualização dos dados na abordagem qualitativa), visando à apresentação e à compreensão da produção científica sobre covid-19 na CI.

\section{RESULTADOS: APRESENTAÇÃO E DISCUSSÃO}

Conforme delimitação estabelecida, foram considerados apenas os artigos publicados em periódicos científicos, totalizando 178 produções. Considera-se este um número expressivo e relevante para o período coberto, tendo em vista que o processo de publicação científica compreende desde a concepção da ideia do artigo até a coleta de dados e a produção do artigo, bem como todo o desenvolvimento de avaliação e revisão do manuscrito. Assim, em aproximadamente um ano foram publicados 178 artigos em 31 periódicos científicos na área da CI, concentrando-se majoritariamente na área de comunicação e informação da Coordenação de Aperfeiçoamento de Pessoal de Nível Superior (Capes). Os periódicos, o estrato Qualis Periódico e o total de artigos publicados em cada revista é apresentado na tabela a seguir. 


\section{Tabela 2 - Periódicos que publicaram artigos sobre covid-19}

\begin{tabular}{|c|c|c|c|}
\hline No & Nome do periódico & $\begin{array}{l}\text { Qualis } \\
\text { periódico }\end{array}$ & $\begin{array}{l}\text { Total de } \\
\text { artigos }\end{array}$ \\
\hline 1. & Liinc em Revista & B1 & 31 \\
\hline 2. & Revista Fontes Documentais & - & 28 \\
\hline 3. & AtoZ: Novas Práticas em Informação e Conhecimento & B2 & 16 \\
\hline 4. & Revista Cubana de Información en Ciencias de la Salud (Cuba) & B1 & 13 \\
\hline 5. & Folha de Rosto & B5 & 10 \\
\hline 6. & Hipertext.net & - & 10 \\
\hline 7. & P2P \& INOVAÇÃO & C & 10 \\
\hline 8. & Revista Eletrônica de Comunicação, Informação e Inovação em Saúde (Reciis) & B1 & 9 \\
\hline 9. & Páginas a\&b: Arquivos e Bibliotecas & B4 & 8 \\
\hline 10. & Rebecin: Revista Brasileira de Educação em Ciência da Informação & B5 & 7 \\
\hline 11. & Biblioteca Universitária & - & 5 \\
\hline 12. & Cadernos de Informação Jurídica (Cajur) & - & 5 \\
\hline 13. & Informação \& Informação & A2 & 3 \\
\hline 14. & Pesquisa Brasileira em Ciência da Informação e Biblioteconomia & B1 & 3 \\
\hline 15. & Informação em Pauta & B5 & 2 \\
\hline 16. & Logeion: Filosofia da Informação & B5 & 2 \\
\hline 17. & Revista Interamericana de Bibliotecología & A2 & 2 \\
\hline 18. & ÁGORA: Arquivologia em debate & B1 & 1 \\
\hline 19. & AWARI & - & 1 \\
\hline 20. & Biblionline & B5 & 1 \\
\hline 21. & Convergências em Ciência da Informação & - & 1 \\
\hline 22. & Em Questão & A2 & 1 \\
\hline 23. & Encontros Bibli: Revista Eletrônica de Biblioteconomia e Ciência da Informação & $A 2$ & 1 \\
\hline 24. & Iberoamerican Journal of Science Measurement and Communication & - & 1 \\
\hline 25. & Memória e Informação & - & 1 \\
\hline 26. & Múltiplos Olhares em Ciência da Informação & B5 & 1 \\
\hline 27. & RDBCI: Revista Digital de Biblioteconomia e Ciência da Informação & B1 & 1 \\
\hline 28. & Revista ACB: Biblioteconomia em Santa Catarina & B2 & 1 \\
\hline 29. & Revista Bibliomar & - & 1 \\
\hline 30. & Revista Brasileira de Biblioteconomia e Documentação & B1 & 1 \\
\hline \multirow[t]{2}{*}{31.} & $\begin{array}{l}\text { Revista Eletrônica Internacional de Economia Política da Informação, da } \\
\text { Comunicação e da Cultura }\end{array}$ & - & 1 \\
\hline & Total & & 178 \\
\hline
\end{tabular}

Fonte: elaboração pelo autor a partir dos dados extraídos na Brapci (2021). ${ }^{1}$

Na Tabela 2 é possível visualizar a distribuição dos artigos em diversos periódicos, demonstrando um esforço coletivo tanto das comunidades científicas quanto das próprias revistas para disseminar resultados de pesquisa sobre covid-19. Alguns periódicos destacam-se entre os demais devido ao número de artigos publicados, como é o caso da Liinc em Revista (31) uma publicação do Instituto Brasileiro de Informação em Ciência e Tecnologia (Ibict), editada por seu Programa de Pós-Graduação em Ciência da Informação

\footnotetext{
1 Refere-se ao quadriênio 2013-2016, publicado na Plataforma Sucupira. Houve casos de periódicos ainda não avaliados pela Capes. Alguns periódicos ainda não possuem estratificação.
} 
(PPGCI), desenvolvido em associação com a Universidade Federal do Rio de Janeiro (UFRJ); e o da Revista Fontes Documentais (28), organizada pelo Grupo de Estudos e Pesquisas em História das Bibliotecas de Ensino Superior (Gephibes), vinculado ao Instituto Federal de Sergipe (IFS). Estes dois periódicos concentram 59 artigos (aproximadamente 30\%) do total encontrado: 178. Este índice também confirma a Lei de Price, de acordo com a qual 50\% ou mais dos artigos são publicados pelos canais com o maior número de publicações (PRICE, 1963; URBIZAGÁSTEGUI ALVARADO, 2009).

Na sequência, incidem os demais periódicos, sendo que alguns deles organizaram edições/números especiais voltados para o tema pesquisado. Os periódicos que organizaram números especiais ao longo de 2020 são:

a) AtoZ: Novas Práticas em Informação e Conhecimento - Práticas informacionais interdisciplinares no contexto do coronavírus (covid-19): artigos e short papers (v. 9, n. 2, 2020). O periódico AtoZ é publicado pelo Programa de Pós-Graduação, Mestrado em Ciência, Gestão e Tecnologia da Informação da Universidade Federal do Paraná (UFPR), em Curitiba, e nesse número especial publicou 16 trabalhos, entre os quais 10 artigos no formato completo e 6 'resumos expandidos';

b) Folha de Rosto - Informação, Tecnologia e Políticas Educacionais em Tempos de Pandemia - LTI Digital (v. 6, n. 2, 2020). A revista Folha de Rosto é publicada pelo Programa de Pós-Graduação em Biblioteconomia (PPGB), por meio do Mestrado Profissional em Biblioteconomia, da Universidade Federal do Cariri (UFCA), no Ceará, e no referido número temático publicou 11 artigos;

c) Hipertext.net - Covid-19 y comunicación (n. 21, 2020). O periódico é publicado pelo Grupo de Pesquisa em Documentação Digital e Comunicação Interativa (DigiDoc), que faz parte do Departamento de Documentação de Mídia e Formatos Digitais do Departamento de Comunicação da Universitat Pompeu Fabra (UPF), de Barcelona/Espanha; nesse número especial, publicou 14 trabalhos, sendo 10 artigos no formato completo e quatro 'resumos expandidos';

d) Liinc em Revista - Prspectivas e desafios informacionais em tempos da pandemia da covid-19 (v. 16, n. 2, 2020). Publicação do convênio entre o PPGCI/Ibict e a UFRJ, nesse dossiê publicou 35 artigos;

e) P2P \& Inovação - A pandemia por covid-19: desafios e oportunidades (v. 7, 2020). Esse periódico é vinculado ao Grupo de Pesquisa Economias Colaborativas e Produção P2P no Brasil, também do Ibict. No referido número publicou 14 artigos;

f) Rebecin: Revista Brasileira de Educação em Ciência da Informação - Ideias inovadoras e caminhos possíveis na docência e na pesquisa em tempos de covid-19 (v. 7, n. 1, 2020). A Rebecin é publicada pela Associação Brasileira de Educação em Ciência da Informação (AbecinN) e publicou oito artigos no número especial;

g) Revista Cubana de Información en Ciencias de la Salud (Cuba) - Ciencia de la información y covid-19 (v. 31, n. 3, 2020). O periódico é editado pelo Centro Nacional de Informação em Ciências Médicas (Infomed) de Cuba e no referido número publicou 15 artigos.

Diante do contexto pandêmico, “[...] as revistas estão reduzindo o tempo de revisão por pares e publicando preprints, com prioridade às publicações relacionadas à covid-19 [...]” (BERMÚDEZ-RODRÍGUEZ, 2020, p. 2). Verifica-se, desse modo, o esforço empreendido por tais periódicos para divulgar resultados de pesquisas vinculados à pandemia de covid-19 e voltados para as áreas de informação e comunicação. Cabe destacar a contribuição dessas revistas, tendo em vista que reúnem em um fascículo diversos artigos sobre uma temática em comum.

Ainda que não tenha destinado um número especial à temática, a Revista Fontes Documentais publicou no formato de artigos, as palestras e as comunicações apresentadas no V Colóquio Internacional 'A 
Medicina na Era da Informação' (V MEDINFOR VINTE VINTE), organizado pela Universidade Federal da Bahia (UFBA), Salvador, e a Universidade do Porto (U.Porto), Portugal. Nos anais, houve muitos trabalhos voltados a covid-19, sobretudo, na sessão temática I, intitulada Coronavírus - Covid-19: Informação e Saúde.

Vitón-Castillo et al. (2020) caracterizaram a produção científica sobre covid-19 publicada em revistas estudantis cubanas e, a partir de estudo bibliométrico, identificaram 22 artigos. Costa et al. (2020) investigaram a produção científica em periódicos online sobre o novo coronavírus nas bases de dados Embase, Medical Literature Analysis and Retrieval System Online/PubMed-Medline, SciELO, Scopus e Web of Science e identificaram 110 publicações. Torres Pascual e Torrell-Vallespín (2020) avaliaram a produção científica latino-americana e caribenha sobre a covid-19 na base de dados PubMed e encontraram 257 trabalhos, publicados em 155 periódicos. Ortiz-Núñez (2020) caracterizou a produção científica sobre a covid-19 na base de dados Scopus no período de 2019 a abril de 2020 e identificou 676 artigos. BermúdezRodríguez et al. (2020) analisaram o impacto do acesso aberto na produção e difusão do conhecimento sobre covid-19 na PubMed e Scopus e obtiveram 6.631 artigos, sendo 4.692 com acesso aberto e 1.939 com acesso fechado.

Os dados aqui expostos representam e reforçam o esforço dos pesquisadores para debater uma temática emergente e necessária no cenário global. Observa-se que, além do fator Qualis Periódico, outros elementos foram levados em consideração pelos autores ao escolherem a revista a que o artigo seria submetido, como: foco e escopo, chamada para número especial, fator de impacto, visibilidade e menção nas redes sociais, entre outros. Esta afirmação se sustenta nos resultados apresentados na Tabela 2, visto que as revistas que publicaram mais artigos na temática ou que organizaram números especiais, não estão classificadas no estrato A da Capes, da área de comunicação e informação, ou mesmo ainda nem possuem estratificação. O panorama do Qualis Periódico pode ser observado no gráfico a seguir.

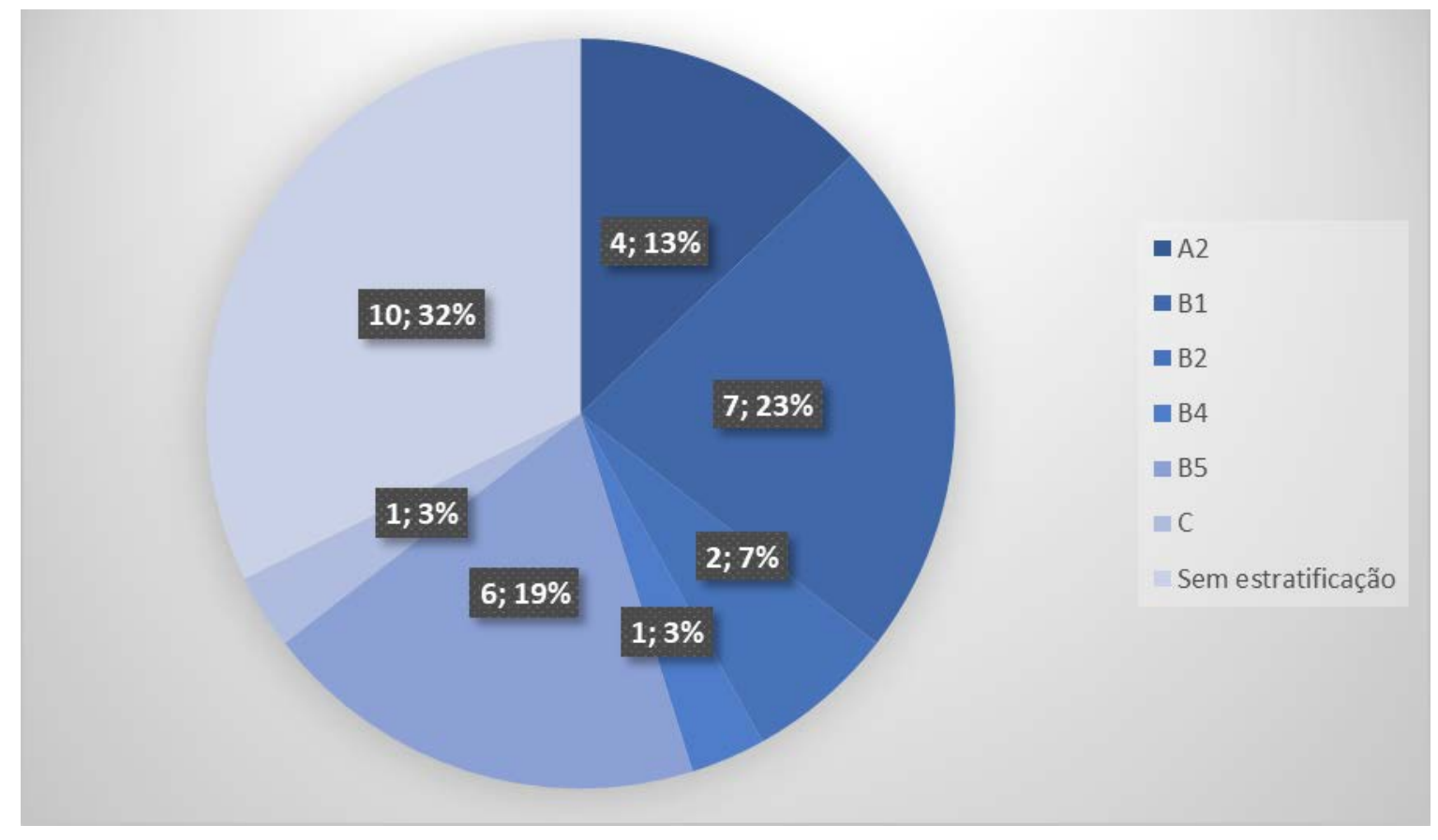

Figura 1 - Quantidade de periódicos e estrato Qualis

Fonte: elaboração do autor a partir do Qualis Periódicos (2013-2016) da Plataforma Sucupira.

Com base no estrato disponível, referente ao quadriênio 2013-2016, tem-se que das 31 revistas quatro são A2, sete são B1, duas são B2, uma é B4, seis são B5, uma é C e 11 ainda não possuem estratificação. Verifica-se que das sete revistas que organizaram números especiais ou dossiês temáticos, duas são B1, duas 
são B5, uma é B2, uma é C e uma ainda não apresenta estratificação. Assim, depreende-se que os autores se ativeram não apenas ao Qualis da revista em si, mas também a outros elementos, como o foco e o escopo da revista, a oportunidade de publicar resultados de pesquisa em um número temático, entre outros aspectos. Esse resultado também foi evidenciado por Bermúdez-Rodríguez et al. (2020); de acordo com eles, as publicações de autores brasileiros sobre a covid-19, independentemente de sua acessibilidade (se via acesso aberto ou não), concentram-se em revistas consideradas de menor prestígio, isto é, com fator de impacto baixo ou sem impacto.

A constituição das autorias dos artigos compreende desde autorias únicas/autorias individuais até múltiplas autorias, sendo 12 o número máximo de autores encontrado como responsáveis por um mesmo artigo. A seguir, um gráfico ilustra a constituição de autorias.

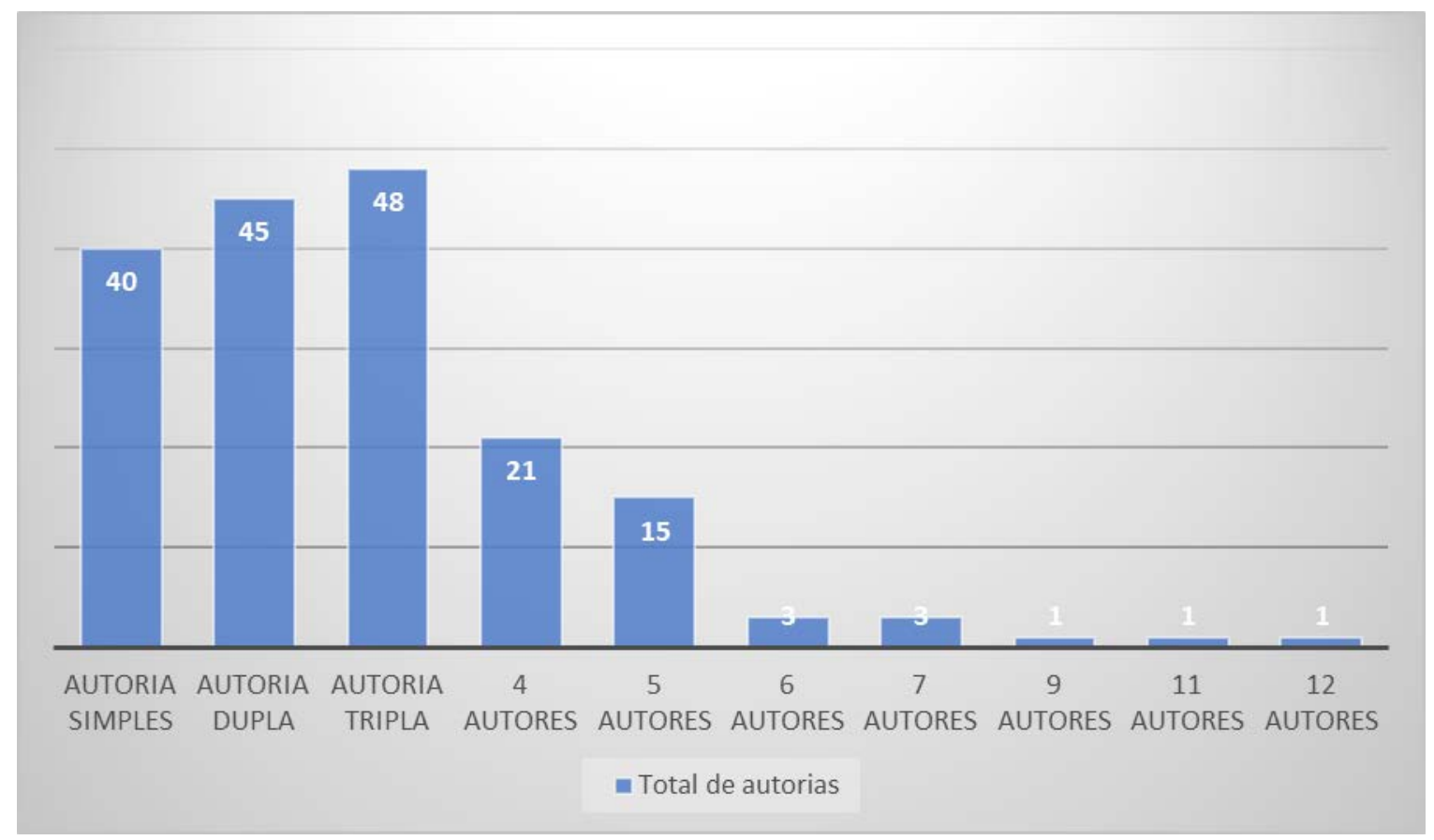

Figura 2 - Constituição de autorias Fonte: elaboração do autor.

Verifica-se que 74,72\% (133) dos 178 artigos que compuseram a amostra deste estudo são constituídos por autoria simples (40), autorias duplas (45) e autorias triplas (48). Vitón-Castillo et al. (2020) identificaram que 54,55\% dos 22 artigos, publicados em revistas estudantis cubanas, foram assinados por dois autores. Ortiz-Núñez (2020) também identificou que a autoria individual sobre covid-19 é muito escassa (1,50\%), predominando a múltipla autoria (98,50\%), bem como para Costa et al. (2020), que as produções em coautoria demonstraram ser expressivamente maior (93,64\%) que as individuais. Esses índices reforçam os resultados de outras pesquisas que analisaram o comportamento e a constituição das autorias na CI e em outros campos do conhecimento, como é o caso de Hilário (2015), Hilário e Grácio (2017) e Mena-Chalco et al. (2014), que também identificaram que o mais comum é a autoria dupla e/ou tripla, o que corrobora os resultados aqui indicados. As autorias individuais/autorias simples apontam como a terceira forma de constituição de autoria mais comum, com um número muito próximo daquelas publicações constituídas por dois ou três autores. Na sequência, incidem os artigos com quatro autores (21), cinco autores (15), seis autores (3), sete autores (3), nove, 11 e 12 autores apenas um cada. Cabe destacar que, nas ciências humanas e nas ciências sociais aplicadas, os casos de autorias constituídas por mais de seis ou sete autores são mais 
raros de ocorrer. No entanto, identifica-se que na CI existem artigos cuja composição se dá com mais de oito autores, como os três casos aqui identificados.

Os 178 artigos abordados aqui foram constituídos por 504 autorias, representadas por pesquisadores brasileiros e estrangeiros. Após listar todas as autorias, agrupar as duplicações e padronizar a grafia dos nomes, agnomes e sobrenomes, chegou-se a um total de 467 autores distintos. Quanto ao ranking de publicação, mesmo que se trate de uma temática recente, houve casos em que algum pesquisador realizou mais de uma produção. Para estabelecer a relação dos mais produtivos, aplicou-se a Lei de Price, ou seja, calculou-se a raiz quadrada do número de autores (467) e, assim, chegou-se ao resultado aproximado de 21. No entanto, este indicador não representaria, de fato, os pesquisadores com mais publicações, visto que muitos (35) apresentaram no mínimo dois artigos. Assim, definiu-se como os mais produtivos aqueles que possuem, pelo menos, três publicações: Clóvis Ricardo Montenegro de Lima (3), Márcio Bezerra da Silva (3) e Rafaela Carolina da Silva (3).

O primeiro, em ordem alfabética, é Clóvis Ricardo Montenegro de Lima (Ibict), com os artigos: 'Contribuição para uma agenda de atenção básica de saúde em tempos de pandemia de covid-19: revisão rápida' (2021); Tensões e conflitos na vigilância digital de pessoas para controle da pandemia de covid-19: a construção de smart cities, humanismo e esfera pública (2020), ambos na Revista P2P \& Inovação. O artigo intitulado 'Emergência de saúde pública global por pandemia de covid-19: desinformação, assimetria de informações e validação discursiva' (2020) foi publicado no periódico Folha de Rosto. Clóvis Lima é um pesquisador sênior do Ibict, tendo publicado todos os artigos como primeiro autor, dois deles constituídos por quatro autores e um por cinco autores.

O segundo é Márcio Bezerra da Silva (UnB) com os seguintes artigos: 'A apresentação de dados abertos sobre a covid-19 pelo governo brasileiro: sinalizações ferramentais' (2020) e 'A presença das fake news em mídias sociais, um extrato de publicações sobre a covid-19 no Facebook' (2020), ambos na Revista Fontes Documentais; e 'A iniciativa digital CONVIDE-i9 no combate à infodemia de covid-19: breves apontamentos de atuação' (2020), na AtoZ: Novas Práticas em Informação e Conhecimento. Márcio Silva é jovem doutor e professor da UnB, tendo publicado um artigo como único autor e os outros dois em coautoria com mais um autor.

A terceira é Rafaela Carolina da Silva (Unesp) com as seguintes produções: 'Arquitetura da informação no contexto da informação em saúde: um olhar para o website do covid-19 no Brasil' (2020), artigo publicado na AtoZ: Novas Práticas em Informação e Conhecimento; 'Motoristas de aplicativos em tempos de covid-19: tendências de informação e prevenção no contexto brasileiro' (2020), publicado na Encontros Bibli; e 'Hibridez em tempos de pandemia: como as tecnologias aproximam as bibliotecas da sociedade' (2020), publicado pela Liinc em Revista. Rafaela Silva é doutoranda pela Unesp e publicou todos os artigos em coautoria, sendo cada artigo escrito por dois e cinco autores. Cabe ressaltar ainda que os referidos pesquisadores não apresentam produção em coautoria conjunta.

Do total de artigos (9) produzidos por esses três autores, dois foram publicados na Revista P2P \& Inovação, dois na Revista Fontes Documentais, dois na Revista AtoZ: Novas Práticas em Informação e Conhecimento. Por sua vez, as revistas Folha de Rosto, Encontros Bibli e Liinc em Revista publicaram somente um artigo cada. Cabe lembrar que, entre esses periódicos, somente um não organizou um número especial/dossiê temático sobre a pandemia covid-19.

Em um cenário mais abrangente, Torres Pascual e Torrell-Vallespín (2020) evidenciaram que os autores mais produtivos na América Latina possuem 10 ou mais publicações. Ortiz-Núñez (2020) identificou que os autores mais produtivos na Scopus apresentaram entre 3 e 11 publicações.

Devido ao presente estudo abarcar o período de 2020 a maio de 2021, foram identificados 156 artigos referentes ao ano de 2020 e 22 a 2021, visto que este se encontra em andamento. Quanto ao idioma 
dos artigos, a maioria é escrita em português, com alguns casos de publicação em dois idiomas, com predominância do espanhol e, depois, do inglês.

Foram empregadas 775 palavras-chave, apresentando uma média de quatro termos por artigo. Após unificar e padronizar os descritores, chegou-se a um total de 459 palavras distintas. Ao aplicar a Lei de Price, verificou-se que 21 seriam os termos mais expressivos. No entanto, teve-se que aumentar esse índice para contemplar os 23 termos mais utilizados pelos autores para descreverem o conteúdo dos artigos no mínimo quatro vezes. Tais termos podem ser visualizados na nuvem de palavras a seguir.

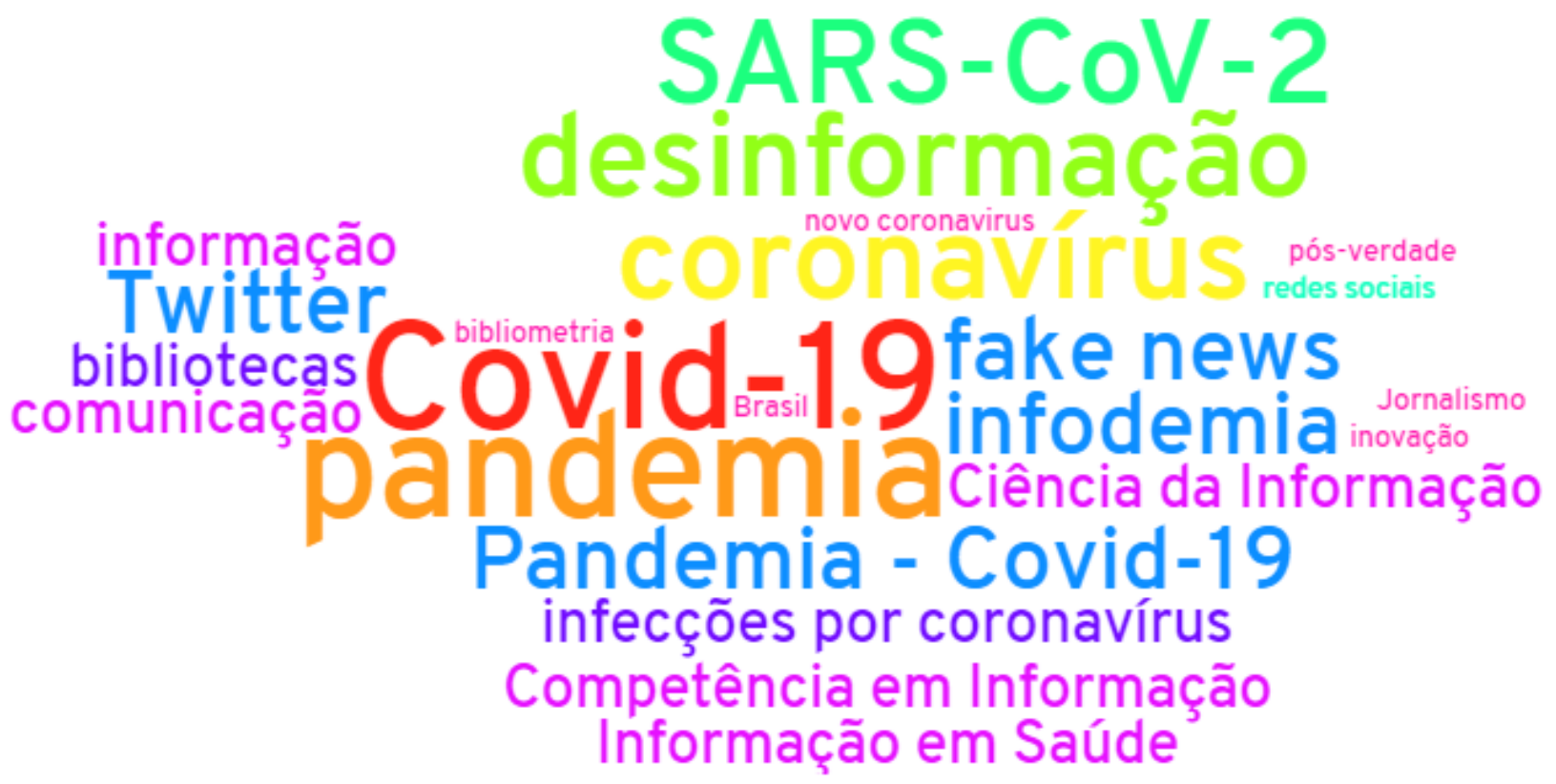

Figura 3 - Nuvem dos termos descritores mais empregados

Fonte: elaboração do autor em WordClouds.com.

A Figura 3 apresenta uma nuvem de palavras com os termos descritores mais empregados nos artigos. O tamanho dos termos na nuvem refere-se diretamente ao número de vezes que eles são usados como descritores e as cores indicam que os termos foram usados em igual número. Por ordem de ocorrência, tem-se: Covid-19 (104), pandemia (34), coronavirus (33), desinformação (21), Sars-CoV-2 (11), redes sociais (9), fake news (8), infodemia (8), Pandemia - Covid19 (8), Twitter (8), Bibliotecas (6), Infecções por coronavírus (6), Ciência da Informação (5), Competência em Informação (5), Comunicação (5), Informação (5), Informação em Saúde (5), Bibliometria (4), Brasil (4), Inovação (4), Jornalismo (4), novo coronavirus (4) e Pós-verdade (4). A partir da análise das palavras-chave identifica-se, de modo geral, uma predominância em relação à discussão de assuntos como informações falsas veiculadas em redes e mídias sociais, a interferência da mídia nesse cenário e a necessidade de saber discernir o que são ou não fake news.

Ao analisar os títulos, resumos e, quando necessário, o texto na íntegra dos artigos, foi possível classificar tematicamente os assuntos discutidos em 13 categorias, indicadas pela predominância em relação ao corpus analisado: atuação profissional durante a pandemia; políticas de informação; informação sobre covid-19; análise de dados em redes/mídias sociais; ensino remoto em tempos de pandemia; infodemia e desinformação; análise de portais de notícias; EMI; estudos aplicados a casos de contágio; desigualdades sociais na pandemia; leitura e literatura; organização e representação da informação e do conhecimento; e memória. Estas categorias são gerais e contemplam diversos temas e aspectos, conforme se comenta a seguir. 
a) Atuação profissional durante a pandemia: apresenta discussões e relatos de atuação de distintos profissionais durante a pandemia: arquivistas, bibliotecários, jornalistas. Também compreende as ações empreendidas por diferentes organizações, como: arquivos (públicos, pessoais e universitários), bibliotecas (públicas, escolares, universitárias), jornais e museus. De forma geral, os estudos classificados nessa categoria discutem as possibilidades de atuação tanto de profissionais quanto de organizações a partir das ações inovadoras empreendidas durante a pandemia. Mais especificamente, no caso das unidades de informação, as pesquisas contemplam ações de mediação da informação, conservação, preservação (física e digital), salvaguarda, gestão de coleções, atuação em redes e mídias sociais, hibridez. Os casos de ações institucionais envolvem a extensão universitária e, como exemplo, menciona-se o carro biblioteca da Universidade Federal de Minas Gerais (UFMG);

b) Políticas de informação: compreende os estudos que discutem o direito à informação, acesso à informação, acessibilidade, inclusão, propriedade intelectual, direitos autorais, patentes, leis de proteção de dados, ciência aberta, dados abertos e gestão de dados aplicados ao contexto pandêmico e às ações empreendidas tanto por organizações privadas quanto públicas visando ao acesso gratuito e democrático à informação confiável e de qualidade relacionada à Covid-19. Além disso, alguns desses estudos discorrem também sobre o processo de solicitação de patentes e registro de vacinas;

c) Informação sobre covid-19: contempla as iniciativas governamentais ou não que visam informar a população sobre a covid-19 e o cuidado à saúde, desde informações referentes às formas de contágio, sintomas, cuidados primários, ciclo da doença, cuidados com automedicação. As iniciativas comentadas nos artigos envolvem o trabalho de observatórios científicos e a divulgação de informação científica, criação de podcasts e realização de webnarios e lives, uso de infográficos e grafos como forma de popularização científica, o papel da imprensa no enfrentamento à pandemia e ações em sistemas penitenciários;

d) Análise de dados em redes/mídias sociais: abarca os estudos que analisam tendências de busca, estratégias de comunicação, práticas informacionais e o comportamento dos usuários, seus sentimentos e estados emocionais, engajamento, discursos, memes e narrativas, fact-cheking. Em adição a tais estudos, inserem-se aqueles que investigam a vigilância digital, o fenômeno da desinformação e a pós-verdade. Incidem ainda nessa categoria os artigos que discutem assuntos mais específicos, como a mineração de dados, a websemântica e o Linked-Data. Quanto às redes/ mídias sociais investigadas, identifica-se uma predominância de análise do Facebook e, em seguida, do Twitter e do Instagram.

e) Ensino remoto em tempos de pandemia: compreende as pesquisas teóricas e os relatos de experiência sobre a atuação no contexto do ensino, desde a educação infantil até a educação no ensino superior. Discutem os desafios e as possibilidades enfrentados pelos professores e estudantes no contexto pandêmico, enfatizando o uso de recursos e plataformas tecnológicos, tecnologias digitais de informação e comunicação e a mediação tecnológica. Além disso, inserem-se também os estudos que relatam as práticas do estágio supervisionado em biblioteconomia, por exemplo.

f) Infodemia e desinformação: contempla as discussões sobre o fenômeno denominado 'infodemia', a desinformação, a propagação de fake news, a pós-verdade, o negacionismo científico. Muitos artigos relacionam a este cenário os programas e as ações de desenvolvimento da competência em informação e o letramento informacional como possíveis soluções para amenizar a infodemia e a desinformação. 
g) Análise de portais de notícias: apresenta a análise dos conteúdos veiculados em portais de notícias com finalidades distintas (visualização de dados, auditoria de dados, disseminação da informação científica);

h) Estudos métricos da informação (EMI): compreende os estudos que investigaram a produção científica e tecnológica sobre a covid-19, atendo-se aos estudos e análises da bibliometria, altmetria e de prospecção. Além desses, incidem as pesquisas sobre o impacto das publicações em acesso aberto e que evidenciam o caráter multidisciplinar da pesquisa sobre o coronavírus. As bases de dados e de patentes utilizadas como fonte de coleta foram principalmente a PubMed e a Scopus, seguidas pelo Portal de Periódicos da Capes, Web of Science, Espacenet e European Patente Office.

i) Estudos aplicados a casos de contágio: contempla as pesquisas que estudaram o perfil dos pacientes contaminados, o perfil epidemiológico dos casos e o contexto de saúde digital e telemedicina.

j) Desigualdades sociais na pandemia: envolve os estudos que destacam a desigualdade social de determinados grupos sociais no enfrentamento à pandemia. Foram identificados trabalhos que têm como objeto de análise a população negra, a população indígena e os grupos marginalizados. Além disso, um estudo, especificamente, trata das questões de gênero e da violência doméstica contra a mulher na pandemia. Há um estudo que aborda o atendimento prestado por centros de assistência social a diferentes populações.

k) Leitura e literatura: compreende as discussões sobre o modo como a leitura e a literatura podem amenizar os sentimentos de angústia, solidão e medo durante a pandemia, bem como contribuem para uma boa saúde mental dos indivíduos. Como exemplo, menciona-se a prática da biblioterapia e da retratação da pandemia em histórias em quadrinhos e na literatura de cordel.

1) Organização e representação da informação e do conhecimento: apresenta os trabalhos que analisam elementos específicos que permeiam, direta ou indiretamente, o campo da organização e representação da informação e do conhecimento, como: representação temática da informação, arquitetura da informação e análise de metadados e interoperabilidade.

m)Memória: contempla os estudos que resgatam tanto a memória de outras pandemias, quanto as memórias educacionais constituídas na pandemia, pseudomemórias, até a memória da dor, por exemplo, relatada por profissionais da saúde.

Constata-se, a partir do exposto, que as categorias denotam uma multiplicidade de olhares na investigação científica sobre a covid-19. Os autores dos artigos selecionaram objetos, corpus, fenômenos, discursos distintos e aplicaram a eles, também, técnicas de análise e interpretações diversas. Isto evidencia a contribuição das pesquisas no âmbito da CI para a ciência como um todo, seja abordando aspectos mais específicos do seu campo disciplinar ou mesmo quando discute elementos mais abrangentes. Isto reforça o caráter social da CI (ARAÚJO, 2014, 2018), porque mostra que, além de ser eminentemente humana e social, apresenta aplicação social (SANTOS NETO et al., 2017). Torres Pascual e Torrell-Vallespín (2020) enfatizam: "Na América Latina, é necessário aumentar o número de investigações sobre covid-19 com autores mais prolíficos para consolidar a literatura sobre o assunto" (tradução nossa).

Devido à seleção feita neste estudo, artigos publicados em uma base de dados da área de CI no Brasil, a maioria dos resultados refere-se às investigações temáticas realizadas por pesquisadores da América Latina, em especial brasileiros, sobre: a atuação profissional durante a pandemia; as políticas de informação; a informação sobre a covid-19; a análise de dados em redes/mídias sociais; o ensino remoto em tempos de pandemia; e a infodemia e a desinformação.

Um dos desafios impostos aos EMI em saúde, sobretudo, aqueles que possuem como foco a covid-19, é que "A atualidade do assunto faz com que a cada dia o número de publicações mude, praticamente na mesma 
proporção que variam os números de afetados e falecidos pela covid-19” (TORRES PASCUAL; TORRELLVALLESPÍN, 2020, tradução nossa), sendo necessário, um acompanhamento e mapeamento constantes do estado da arte na temática. "O ritmo da produção cieaontífica sobre a covid-19 está se multiplicando de forma constante, por isso será objeto de estudos métricos subsequentes" (ORTIZ-NÚÑEZ, 2020).

O Brasil é o país latino-americano que mais publica sobre a temática (BERMÚDEZ-RODRÍGUEZ, 2020; TORRES PASCUAL; TORRELL-VALLESPÍN, 2020); assim, vislumbra-se, mesmo que timidamente, a contribuição da CI nesse cenário.

\section{CONSIDERAÇÕES FINAIS}

Os resultados indicados neste artigo permitem a visualização do panorama da produção científica sobre a covid-19 no âmbito da CI no Brasil, recuperada na Brapci. Foi apresentada a quantidade de artigos publicados, as revistas em que os artigos foram publicados, o número de autores e a constituição das autorias, os autores mais produtivos, as palavras-chave mais empregadas e a categorização temática dos artigos. Para a comunidade científica e profissional da CI, os resultados aqui apresentados permitem a compreensão do que tem sido realizado na área em termos de pesquisa relacionada à covid-19.

Considera-se que a emergência da temática relativa à covid-19 no cenário mundial configura-se como uma das motivações para que os pesquisadores publiquem sobre ela, aproximando-a dos seus interesses de pesquisa. Requere-se, no entanto, realizar uma pesquisa visando auscultar os autores para se obter dados mais precisos em relação às motivações para se pesquisar e publicar estudos relacionados à covid-19. Como pesquisas futuras no âmbito dos EMI em saúde, voltados para a pandemia de covid-19 especialmente, são muitas as possibilidades. Além daquela indicada anteriormente (investigar a motivação dos autores), é possível apontar: a vinculação dos autores dos artigos à alguma instituição de ensino ou pesquisa que tenha como foco os estudos da informação em saúde; a colaboração científica e a coautoria; a cocitação e acoplamento bibliográfico, estudos altmétricos, entre outros.

Conclui-se que a CI incide como um dos campos do conhecimento que tem se destacado no cenário da produção científica nacional, tendo em vista a expressividade no número de publicações empreendidas em pouco mais de um ano. Esse cenário demonstra o esforço coletivo de pesquisadores, estudantes, instituições e periódicos científicos da CI em dar visibilidade à ciência produzida predominantemente na esfera pública e, muitas vezes, financiada por agências de fomento.

\section{REFERÊNCIAS}

ALENCAR, Maria Simone de Menezes et al. Análise da produção científica brasileira sobre nanotecnologia e saúde. Revista Eletrônica de Comunicação, Informação e Inovação em Saúde, Rio de Janeiro, v. 11, n. 1, p. 1-16, 2017. DOI: https://doi.org/10.29397/reciis.v11i1.1199. Disponível em: https://www.reciis.icict.fiocruz. br/index.php/reciis/article/view/1199. Acesso em: 11 maio 2021.

ARAÚJO, Carlos Alberto Ávila. Arquivologia, Biblioteconomia, Museologia e Ciência da Informação: o diálogo possível. Brasília, DF: Briquet de Lemos Livros; São Paulo: Abrainfo, 2014.

ARAÚJO, Carlos Alberto Ávila. O que é Ciência da Informação. Belo Horizonte: KMA, 2018.

ARAÚJO, Kizi Mendonça de et al. A produção científica sobre zika em periódicos de acesso aberto. Revista Eletrônica de Comunicação, Informação e Inovação em Saúde, Rio de Janeiro, v. 11, n. especial, p. 1-8, 2017. DOI: https://doi.org/10.29397/reciis.v11i0.1391. Disponível em: https://www.reciis.icict.fiocruz.br/ index.php/reciis/article/view/1391. Acesso em: 11 maio 2021.

BERMÚDEZ-RODRÍGUEZ, Tatiana et al. O impacto do acesso aberto na produção e difusão de conhecimento sobre a covid-19. Liinc em Revista, Rio de Janeiro, v. 16, n. 2, p. e5296, 11 dez. 2020. DOI: https://doi. org/10.18617/liinc.v16i2.5296. Disponível em: http://revista.ibict.br/liinc/article/view/5296. Acesso em: 11 maio 2021. 
BUFREM, Leilah Santiago. A pandemia da covid-19 no Brasil: informações e contradições na atual conjuntura. P2P e Inovação, Rio de Janeiro, v. 7, n. 1, p. 101-120, 26 set. 2020. DOI: https://doi.org/10.21721/p2p.2020v7n1. p101-120. Disponível em: http://revista.ibict.br/p2p/article/view/5461/5073. Acesso em: 11 maio 2021.

COSTA, Isabelle Cristinne Pinto et al. Produção científica em periódicos online sobre o novo coronavírus (covid-19): pesquisa bibliométrica. Texto \& Contexto - Enfermagem, Florianópolis, v. 29, p. e20200235, 2020. DOI https://doi.org/10.1590/1980-265x-tce-2020-0235. Disponível em: https://www.scielo.br/pdf/tce/ v29/1980-265X-tce-29-e20200235.pdf. Acesso em: 11 maio 2021.

COVID-19 PANDEMIC DATA. In: WIKIPEDIA: the free encyclopedia. [San Francisco, CA: Wikimedia Foundation, c2021]. Disponível em: https://en.wikipedia.org/wiki/Template:COVID-19 pandemic data. Acesso em: 28 jul. 2021.

FREITAS, Juliana Lazzarotto; BUFREM, Leilah Santiago; GRÁCIO, Maria Cláudia Cabrini. O interdomínio dos estudos métricos da informação em medicina: aproximação entre discurso e prática de seus pesquisadores. Encontros Bibli: revista eletrônica de biblioteconomia e ciência da informação, Florianópolis, v. 24, n. 56, p. 01-22, 2019. DOI: https://doi.org/10.5007/1518-2924.2019.e65348. Disponível em: https://periodicos. ufsc.br/index.php/eb/article/view/1518-2924.2019.e65348. Acesso em: 29 jul. 2021.

GIL, Antonio Carlos. Como elaborar projetos de pesquisa. 4. ed. São Paulo: Atlas, 2008.

HILÁRIO, Carla Mara. A presença da colaboração científica em pesquisas brasileiras: um estudo nas áreas de ciência da informação, matemática e odontologia. 2015. 150 f. Dissertação (Mestrado em Ciência da Informação) - Faculdade de Filosofia e Ciências, Universidade Estadual Paulista Júlio de Mesquita Filho, Marília, 2015. Disponível em: http://hdl.handle.net/11449/126603. Acesso em: 11 maio 2021.

HILÁRIO, Carla Mara; GRÁCIO, Maria Cláudia Cabrini. Colaboração científica em pesquisas brasileiras: um estudo comparativo nas áreas de ciência da informação, matemática e odontologia. Scientometrics, [s. I.], v. 113, n. 2, p. 929-950, 2017. DOI: http://dx.doi.org/10.1007/s11192-017-2498-4. Disponivel em: http://hdl. handle.net/11449/179150. Acesso em: 11 maio 2021.

MARTINS, Maria de Fátima Moreira. Análise bibliométrica de artigos científicos sobre o vírus Zika. Revista Eletrônica de Comunicação, Informação e Inovação em Saúde, Rio de Janeiro, v. 10, n. 1, p. 1-9, 2016. DOI: https://doi.org/10.29397/reciis.v10i1.1096. Disponível em: https://www.reciis.icict.fiocruz.br/index.php/ reciis/article/view/1096. Acesso em: 10 maio 2021.

MENA-CHALCO, Jesus Pascual et al. Brazilian bibliometric coauthorship networks. Journal of the

Association for Information Science and Technology, [s. I.], v. 65, n. 7, p.1424-1445, 2014. DOI: https://doi. org/10.1002/asi.23010. Disponível em: https://asistdl.onlinelibrary.wiley.com/doi/10.1002/asi.23010. Acesso em: 26 nov. 2021.

NORONHA, Daisy Pires; MARICATO, João de Melo. Estudos métricos da informação: primeiras aproximações. Encontros Bibli: revista eletrônica de biblioteconomia e ciência da informação, Florianópolis, n. esp., $1^{\circ}$ sem. 2008. DOI: https://doi.org/10.5007/1518-2924.2008v13nesp1p116. Disponível em: https://periodicos.ufsc. br/index.php/eb/article/view/1518-2924.2008v13nesp1p116. Acesso em: 10 maio 2021.

OLIVEIRA, Ely Francina Tannuri de. Estudos métricos da informação no Brasil: indicadores de produção, colaboração, impacto e visibilidade. Marília: Oficina Universitária; São Paulo: Cultura Acadêmica, 2018. Disponível em: https://www.marilia.unesp.br/Home/Publicacoes/estudos-metricos-da-informacao-no-brasil--e-book.pdf. Acesso em: 10 maio 2021.

OLIVEIRA, Dalgiza Andrade de; ARAÚJO, Ronaldo Ferreira de. A contribuição das métricas para o campo da ciência da informação. Perspectivas em Ciência da Informação, Belo Horizonte, v. 25, núm. esp., p. 300318, fev. 2020. Disponível em: https://periodicos.ufmg.br/index.php/pci/article/view/22293/17910. Acesso em: 10 maio 2021.

OLIVEIRA, Ely Francina Tannuri de; GRACIO, Maria Cláudia Cabrini. Indicadores bibliométricos em ciência da informação: análise dos pesquisadores mais produtivos no tema estudos métricos na base Scopus.

Perspectivas em Ciência da Informação, Belo Horizonte, v. 16, n. 4, p. 16-28, out./dez. 2011. Disponível em: http://portaldeperiodicos.eci.ufmg.br/index.php/pci/article/view/1299/969. Acesso em: 08 maio. 2021.

ORTIZ-NUNEZ, Roelvis. Análisis métrico de la producción científica sobre covid-19 en Scopus. Revista Cubana de Información en Ciencias de la Salud, La Habana, v. 31, n. 3, p. e1587, 2020. Disponível em: http://scielo.sld.cu/scielo.php?script=sci arttext\&pid=S2307-21132020000300002\&lng=es\&nrm=iso. Acesso em: 08 maio. 2021. 
PINTO, Virgínia Bentes; CAVALCANTE; Lídia Eugênia. Pesquisa bibliográfica e documental: o fazer científico em construção. In: PINTO, Virgínia Bentes; VIDOTI, Silvana Aparecida Borsetti Gregório; CAVALCANTE, Lídia Eugênia (org.). Aplicabilidades metodológicas em Ciência da Informação. Fortaleza: UFC, 2015. p. 15-34.

PRICE, Derek J. de Solla. Little science, big science. Nova York: Columbia University Press, 1963.

SANTIN, Dirce Maria; NUNEZ, Zizil Arledi Glienke; MOURA, Ana Maria Mielniczuk de. Produção científica brasileira em células-tronco nos anos 2000 a 2013: características e colaboração internacional. Revista Eletrônica de Comunicação, Informação e Inovação em Saúde, Rio de Janeiro, v. 9, n. 2, p. 1-16, 2015. DOI: https://doi.org/10.29397/reciis.v9i2.965. Disponível em: https://www.reciis.icict.fiocruz.br/index.php/ reciis/article/view/965. Acesso em: 11 maio 2021.

SANTOS, Raimundo Nonato Macedo dos; KOBASHI, Nair Yumiko. Bibliometria, cientometria, infometria: conceitos e aplicações. Tendências da Pesquisa Brasileira em Ciência da Informação, Brasília, DF, v. 2, n. 1, p. 155-172, 2009. Disponível em: https://repositorio.ufpe.br/handle/123456789/10089. Acesso em: 11 maio 2021.

SANTOS NETO, João Arlindo dos et al. Interdisciplinaridade no contexto da ciência da informação: correntes e questionamentos. Em Questão, Porto Alegre, v. 23, n. 1, p. 9-35, 2017. DOI: https://doi.org/10.19132/18085245231.9-35. Disponível em: https://seer.ufrgs.br/index.php/EmQuestao/article/view/62733. Acesso em: 29 jul. 2021.

SOBRAL, Natanael Vitor et al. Produção científica colaborativa na área da saúde tropical: uma análise da rede de colaboração do Programa de Pós-Graduação em Medicina Tropical da Universidade Federal de Pernambuco. Revista Eletrônica de Comunicação, Informação e Inovação em Saúde, Rio de Janeiro, v. 10, n. 1, p. 1-15, 2016. DOI: https://doi.org/10.29397/reciis.v10i1.1025. Disponível em: https://www.reciis. icict.fiocruz.br/index.php/reciis/article/view/1025. Acesso em: 11 maio 2021.

SILVA, Márcia Regina da; HAYASHI, Carlos Roberto Massao; HAYASHI, Maria Cristina Piumbato Innocentini. Análise bibliométrica e cientométrica: desafios para especialistas que atuam no campo. InCID: Revista de Ciência da Informação e Documentação, Ribeirão Preto, v. 2, n. 1, p. 110-129, jan./jun. 2011. DOI: https:// doi.org/10.11606/issn.2178-2075.v2i1p110-129. Disponível em: https://www.revistas.usp.br/incid/article/ view/42337. Acesso em: 28 maio 2021.

TORRES PASCUAL, Cristina; TORRELL-VALLESPIN, Sandra. Análisis bibliométrico de la producción científica latinoamericana y del Caribe sobre covid-19 en PubMed. Revista Cubana de Información en Ciencias de la Salud, La Habana, v. 31, n. 3, p. e1600, set. 2020. Disponível em: http://scielo.sld.cu/scielo.php?script=sci arttext\&pid=S2307-21132020000300008\&lng=es\&nrm=iso. Acesso em: 11 maio 2021.

URBIZAGÁSTEGUI ALVARADO, Ruben. Elitismo na literatura sobre a produtividade dos autores. Ciência da Informação, Brasília, DF, v. 38, n. 2, p. 69-79, maio/ago. 2009. Disponível em: http://revista.ibict.br/ciinf/ article/view/1246. Acesso em: 11 maio 2021

VALENTIM, Marta Lígia Pomim. Construção de conhecimento científico. In: VALENTIM, Marta Lígia Pomim (org.). Métodos qualitativos de pesquisa em Ciência da Informação. São Paulo: Polis, 2005. p. 7-28. (Coleção Palavra-Chave, 16).

VITÓN-CASTILLO, Adrián Alejandro et al. Producción científica sobre covid-19 en revistas estudiantiles cubanas. Revista Cubana de Información en Ciencias de la Salud, La Habana, v. 31, n. 4, p. e1647, 2020. Disponível em: http://scielo.sld.cu/scielo.php?script=sci arttext\&pid=S2307-21132020000400002\&lng=es \&nrm=iso. Acesso em: 11 maio 2021.

VOLPATO, Gilson. Ciência: da filosofia à publicação. 4. ed. Botucatu: Tipomic, 2004. 